Verklärt, verkitscht, vergessen 
Renate Möhrmann (Hrsg.)

\title{
Verklärt, verkitscht, vergessen
}

\author{
Die Mutter als ästhetische Figur
}

Unter Mitarbeit von Barbara Mrytz

Verlag J.B. Metzler

Stuttgart $\cdot$ Weimar 
Die Deutsche Bibliothek - CIP-Einheitsaufnahme

\section{Möhrmann, Renate:}

Verklärt, verkitscht, vergessen : die Mutter als ästhetische Figur / Renate Möhrmann. Unter Mitarb. von Barbara Mrytz. Stuttgart ; Weimar : Metzler, 1996

ISBN 978-3-476-01302-6

ISBN 978-3-476-01302-6

ISBN 978-3-476-03596-7 (eBook)

DOI 10.1007/978-3-476-03596-7

Dieses Werk einschließlich aller seiner Teile ist urheberrechtlich geschützt. Jede Verwertung außerhalb der engen Grenzen des Urheberrechtsgesetzes ist ohne Zustimmung des Verlages unzulässig und strafbar. Das gilt insbesondere für Vervielfältigungen, Übersetzungen, Mikroverfilmungen und die Einspeicherung undVerarbeitung in elekronischen Systemen.

(C) 1996 Springer-Verlag GmbH Deutschland Ursprünglich erschienen bei J.B. Metzlersche Verlagsbuchhandlung und Carl Ernst Poeschel Verlag GmbH in Stuttgart 1996 
Inhalt

\author{
Danksagung \\ IX \\ Renate Möhrmann \\ Einleitung \\ 1
}

\title{
I \\ Der enteignete Leib \\ Himmels- und Märchenmütter
}

\author{
Helga Möbius \\ Mutter-Bilder. \\ Die Gottesmutter und ihr Sohn
}

21

Elke Liebs

Die Un-Mütter der Märchen

39

Barbara Mrytz

"Komm, rat mir doch, Mutter".

Die Mutter in der englisch-schottischen Volksballade des Child-Korpus

57

\section{II \\ Das Programm der Dichter \\ Zur Polarisierung der Geschlechterrollen}

\author{
Renate Möhrmann \\ Die vergessenen Mütter. \\ Zur Asymmetrie der Herzen im bürgerlichen Trauerspiel




\section{Deirdre Vincent \\ Mädchen, Frau, Ehefrau ... \\ Zur Muttergestalt bei Goethe \\ 92}

Barbara Becker-Cantarino

"Meine Mutter, die Hur, die mich umgebracht hat...».

Die Kindsmörderin als literarisches Sujet

108

Pia Kleber

Die Courage der Mütter.

Am Beispiel von Bertolt Brecht

130

\section{III \\ Mütter im Blick der Maler \\ Zwischen Traum und Trauma}

\section{Martina Sitt}

"In meinen Armen, in meinem Schoß«.

Zur Darstellung der Mutterfigur in der Genremalerei

des 17. und 19. Jahrhunderts

145

Doris Hansmann

Die Tötung des Weiblichen im männlichen Schöpfungsmythos.

$\mathrm{Zu}$ den »toten Müttern« bei Egon Schiele

170

\section{Jutta Held}

Politische Aktion und paranoisch-kritische Analyse.

Das Bild der Mutter bei Max Lingner und Salvador Dali 


\title{
IV \\ Posen und Positionen \\ Heldenmütter und ihre ganz gewöhnlichen Schwestern
}

\author{
Jan MacDonald \\ Die Probe und der Suppentopf. \\ Die Schauspielerin als Mutter. Das Beispiel Sarah Siddons \\ 215 \\ Evelyn Deutsch-Schreiner \\ Blonde Mütter für das Reich? \\ Zum Bild der Mutter auf dem NS-Theater \\ 242

\section{V \\ Die neven Massenmütter \\ Ein Blick und die Konsumlust bricht aus}

Cornelia Krauss

"Unsere Mutter bleibt die Beste".

Zum Familienbild in Fernsehserien

261

Sabine Gottgetreu

Traum-Mütter und Mütter-Träume.

Das Beispiel der Nivea-Werbung

275

\section{VI \\ Blickwechsel \\ Zu den Mütterentwürfen der Künstlerinnen}

\author{
Natascha Würzbach \\ Zweihundert Jahre Ringen mit der perfekten Mutter. \\ Die Auseinandersetzung mit dem Mutterbild \\ im englischen Frauenroman des 19. und 20. Jahrhunderts
}


Jula Dech

Die Kollwitz-Mütter.

Rädelsführerin und Mater dolorosa

315

Tanja Frank

Behauptete Mitte.

Die Mutterfiguren Heidrun Hegewalds

334

Renate Berger

Zwischen Leben und Tod.

Zur Mutterimago bei Niki de St. Phalle, Ulrike Rosenbach, Mary Kelly und Annegret Soltau

354

Renate Möhrmann

"Deutschland, bleiche Mutter".

$\mathrm{Zu}$ den Mutterfiguren im neuen deutschen Frauenfilm

372

Abbildungsnachweis

388

Literaturverzeichnis

389

Namenregister

408 


\section{Danksagung}

An dieser Stelle möchte ich mich bei all denen bedanken, die mich während der langjährigen Forschungsarbeit zu diesem Buch nachdrücklich unterstützt haben. Hier sei an erster Stelle mein Mann, Dieter G. Möhrmann, genannt, der immer bereit war, die anliegenden Probleme mit mir zu besprechen und meine zahlreichen $>$ Abwesenheiten ' geduldig ertragen hat. Mein Dank gilt ferner meinen Kölner, meinen Wiener sowie meinen kalifornischen Studentinnen und Studenten, die mich bei meiner mütterlichen Spurensuche mit anhaltendem Interesse begleitet haben. Ausdrücklich möchte ich mich auch beim kanadischen Kultusminister bedanken, der mich mit dem kanadisch-deutschen Wissenschaftspreis (1994/95) ausgezeichnet hat und mir somit die Möglichkeit gab, das Projekt unter besten akademischen Bedingungen fertigzustellen. In diesem Zusammenhang sei auch den Freunden in Toronto gedankt, die mir all die Monate mit ihrer liebevollen Anteilnahme so treu zur Seite standen.

Die Drucklegung wurde ermöglicht durch die freundliche Unterstützung des Ministerpräsidenten von Nordrhein-Westfalen, Johannes Rau, und der Konrad-Adenauer-Stiftung, die sich beide ganz spontan und unbürokratisch von der Wichtigkeit des Themas und dem damit verbundenen Griff ins Schatzkästlein überzeugen ließen. Last but not least gilt mein Dank der Direktorin des Kölner Käthe Kollwitz Museums, Hannelore Fischer, die über die bloße Bildbeschaffung hinaus das Projekt mit zahlreichen Anregungen begleitet hat.

Köln, 1995

Renate Möhrmann 